\title{
Calcium Waves Precede Electrophysiological Changes of Spreading Depression in Hippocampal Organ Cultures
}

\author{
Phillip E. Kunkler ${ }^{1}$ and Richard P. Kraig ${ }^{1,2,3}$ \\ Departments of ${ }^{1}$ Neurology and ${ }^{2}$ Pharmacological and Physiological Sciences, and ${ }^{3}$ Committee on Neurobiology, The \\ University of Chicago, Chicago, Illinois 60637
}

\begin{abstract}
Although intercellular $\mathrm{Ca}^{2+}$ waves resemble spreading depression (SD) and occur in hippocampal organ cultures (HOTCs), SD has not been reported in these cultures. Accordingly, electrophysiological and $\mathrm{Ca}^{2+}$ imaging techniques were used to examine potential interrelations between $\mathrm{Ca}^{2+}$ waves and electrophysiological changes of SD. Our results show, for the first time, that HOTCs can support SD. Furthermore, two distinct $\mathrm{Ca}^{2+}$ waves were found to precede SD. The first traveled $>100$ $\mu \mathrm{m} / \mathrm{sec}$ along the pyramidal cell dendritic layer. The second subsequently traveled mostly perpendicular to the pyramidal cell layer from CA3 (or CA1) but also in all directions from its area of initiation. This second, slower wave spread with the interstitial $D C$ change of $S D$ at millimeters per minute but
\end{abstract}

Slowly propagating intracellular and intercellular $\mathrm{Ca}^{2+}$ waves are a recently recognized phenomenon of neural cells (Cornell-Bell et al., 1990; Charles et al., 1991, 1992, 1996; Cornell-Bell and Finkbeiner, 1991; Finkbeiner, 1992; Enkvist and McCarthy, 1994) and tissues (Dani et al., 1992; Newman and Zahs, 1997), which may be a concomitant of spreading depression (SD) (Nedergaard, 1994). Given the widespread potential signaling capacities of $\mathrm{Ca}^{2+}$ waves (Nedergaard, 1994; Parpura et al., 1994), their detailed study may be a particularly fruitful means to advance the understanding of SD. $\mathrm{Ca}^{2+}$ waves occur within astrocytes and between astrocytes for distances that extend up to $200 \mu \mathrm{m}$ (Newman and Zahs, 1997; Wang et al., 1997). They also occur among neurons. Neuronal $\mathrm{Ca}^{2+}$ waves propagate $\sim 10$ times faster (Charles et al., 1996) than the propagation velocity of $\mathrm{SD}$, so their relation to SD is particularly uncertain. Indeed, the relation of $\mathrm{Ca}^{2+}$ waves to SD has only begun to be defined (Nedergaard et al., 1995). Intercellular $\mathrm{Ca}^{2+}$ waves have not been associated with the electrophysiological criteria of SD. SD classically is defined by electrophysiological criteria as a propagating wave (i.e., 1-6 $\mathrm{mm} / \mathrm{min}$ ) of evoked or spontaneous silence in neuronal fast electrical activity that is associated with a large negative DC potential (Leão, 1944; Bureś et al., 1974).

\footnotetext{
Received Dec. 12, 1997; revised Jan. 27, 1998; accepted Feb. 23, 1998.

This work was supported by the National Institute of Neurological Disorders and Stroke (Grant NS-19108), a Zenith Award from the Alzheimer's Association, and the Brain Research Foundation of the University of Chicago. P.E.K. was supported in part by a National Institutes of Health Research Service Award (NS-10190). We thank several members of our laboratory for their assistance in this project. Ms. Marcia P. Kraig gave assistance in culture preparation and maintenance. A. O. Caggiano critically read a final version of this manuscript. C. D. Lascola suggested that we reduce extracellular volume and cover cultures with a thin layer of mineral oil. Mr. R. Hulse did image analyses and restorations.

Correspondence should be addressed to Dr. Richard P. Kraig, Department of Neurology MC2030, The University of Chicago, 5841 South Maryland Avenue, Chicago, IL 60637.

Copyright (C) 1998 Society for Neuroscience $\quad 0270-6474 / 98 / 183416-10 \$ 05.00 / 0$
}

always ahead of it by $6-16 \mathrm{sec}$. Heptanol, which uncouples gap junctions, blocked both of these $\mathrm{Ca}^{2+}$ waves and SD. Thus, two types of $\mathrm{Ca}^{2+}$ waves occur with the initiation and propagation of SD. The first might reflect interneuronal changes linked by gap junctions, whereas the second might stem from interastrocyte changes linked via similar connections. Because individual cells can be followed in space and time for protracted periods in HOTCs, this preparation may be ideal for studies designed to explore not only the mechanisms of SD but also the long-term consequences of SD, such as ischemic tolerance.

Key words: calcium waves; spreading depression; hippocampal organ cultures; ischemic tolerance; astrocytes; calciumsensitive dyes; Fluo-3

We have developed a highly reproducible model of SD in hippocampal organ cultures (HOTCs) and show, for the first time, that these cultures can elicit recurrent episodes of SD for hours without persistent compromise to normal evoked polysynaptic electrical activity. Furthermore, simultaneous electrophysiological and $\mathrm{Ca}^{2+}$ imaging measurements show that electrical initiation of SD is associated with a fast $(>100 \mu \mathrm{m} / \mathrm{sec})$ wave of $\mathrm{Ca}^{2+}$ rise that moves along the pyramidal cell basilar dendritic layer before electrophysiological changes of SD begin. This wave may reflect changes between neurons (Herreras et al., 1994; Charles et al., 1996). Then a second, slower $\mathrm{Ca}^{2+}$ wave precedes the electrophysiological changes of SD by seconds but propagates at the speed of $\mathrm{SD}(\mathrm{mm} / \mathrm{min})$, mostly perpendicular to the pyramidal cell layer from a focus in CA3 (or less often CA1). The latter $\mathrm{Ca}^{2+}$ waves are reminiscent of those seen among astrocytes. Exposure of HOTCs to glutamate, which evokes $\mathrm{Ca}^{2+}$ waves, failed to induce any electrophysiological changes of SD. Finally heptanol, which inhibits gap junctions, inhibited $\mathrm{Ca}^{2+}$ waves and SD. Thus, $\mathrm{Ca}^{2+}$ waves may be part of second messenger cascades that influence the initiation as well as the propagation of SD.

This work has appeared in abstract form (Kunkler and Kraig, 1997b).

\section{MATERIALS AND METHODS}

HOTC preparation and maintenance. Preparation and maintenance of the HOTCs have been described previously (Kunkler and Kraig, 1997a). Briefly, Wistar rat pups (6-9 d old) were decapitated after halothane anesthesia; the brains were removed and placed into cooled $\left(3^{\circ} \mathrm{C}\right) \mathrm{HBSS}$ supplemented with D-glucose $(6.5 \mathrm{mg} / \mathrm{ml})$. Hippocampi were isolated, placed on agar-coated (3.5\% in $150 \mathrm{~mm} \mathrm{NaCl}$ ) Teflon plates, and sectioned perpendicularly to their septotemporal axis ( $400 \mu \mathrm{m}$ thick). Slices that displayed an intact dentate gyrus (DG) and pyramidal cell layer were transferred to uncoated $30 \mathrm{~mm}$ Millicell-CM tissue culture inserts (Millipore, Bedford, MA) in six-well culture dishes (Becton Dickinson, 
Lincoln Park, NJ). The medium around HOTCs was replaced twice per week $(1.2 \mathrm{ml})$ and contained Eagle's basal medium (50\%), Earle's balanced salt solution (25\%), horse serum $(23 \%), 25 \mathrm{U} / \mathrm{ml}$ penicillin/ streptomycin, and $1 \mathrm{~mm}$ L-glutamine, supplemented with additional D-glucose to a final concentration of $7.5 \mathrm{mg} / \mathrm{ml}$. All tissue culture reagents were obtained from Life Technologies (Grand Island, NY). Slices were maintained at $37^{\circ} \mathrm{C}$ with $5 \% \mathrm{CO}_{2}$ /balanced humidified air in a standard incubator (Heraeus Instruments, South Plainfield, NJ) for $>3$ weeks.

HOTC loading with Fluo-3. HOTCs were loaded with the fluorescent calcium indicator Fluo-3 acetoxymethyl (AM) ester (Molecular Probes, Eugene, OR) in a HEPES buffer [containing (in mM) 10 HEPES, 25 dextrose, $137 \mathrm{NaCl}, 5.3 \mathrm{KCl}, 3 \mathrm{CaCl}_{2}$, and $1 \mathrm{MgCl}_{2}, \mathrm{pH}$ 7.4] (van den Pol et al., 1992). The dye $(50 \mu \mathrm{g} / \mathrm{vial})$ was dissolved in $10 \mu \mathrm{l} \mathrm{DMSO} /$ Pluronic F-127 (2\% w/v) and added to the HEPES buffer to achieve a final concentration of $2 \mu \mathrm{M}$. To facilitate Fluo-3 loading, we placed the solution under the insert $(1.2 \mathrm{ml})$; we placed an additional $0.5 \mathrm{ml}$ on top. Dye penetration into HOTCs was enhanced further by gentle tilting $(0.1$ $\mathrm{Hz}$ ) of the culture dish on a rocker platform at room temperature during loading. After a $30 \mathrm{~min}$ incubation, free dye was washed out with three rinses of HEPES buffer over 30 min while the rocking continued. The HOTC, with its insert, was transferred to a $35 \mathrm{~mm}$ culture dish and perfused with recording solution (see below) at $36 \pm 1{ }^{\circ} \mathrm{C}$ for an additional $30 \mathrm{~min}$ before use.

Electrical stimulation. For electrophysiological studies, HOTCs (maintained in vitro for $21-60 \mathrm{~d}$ ) were placed in $35 \mathrm{~mm}$ culture dishes mounted in a movable open perfusion microincubator (PDMI-2; Medical Systems, Greenvale, NY) on an inverted microscope (Flouvert UV; Leica Mikroskopie und Systeme GmbH, Wetzlar, Germany). The cultures were perfused $(1 \mathrm{ml} / \mathrm{min})$ with a normal Ringer's solution of (in $\mathrm{mM}$ ): 124 $\mathrm{NaCl}, 2 \mathrm{KCl}, 26 \mathrm{NaHCO}_{3}, 2.5 \mathrm{CaCl}_{2}, 1 \mathrm{MgCl}_{2}, 1.25 \mathrm{KH}_{2} \mathrm{PO}_{4}$, and 6 glucose, adjusted to $\mathrm{pH} 7.4$ with $5 \% \mathrm{CO}_{2} / 95 \% \mathrm{O}_{2}$. Normal Ringer's also contained $25 \mu \mathrm{M}$ isoproterenol (ISO). Stock solutions of ISO (100 mM) were prepared freshly and protected from the light. After being superfused within the insert for $30 \mathrm{~min}$ to rinse excess dye further, the Ringer's solution was directed outside (i.e., around and beneath) the insert and continued to flow at $1-2 \mathrm{ml} / \mathrm{min}$. Next, an interstitial microelectrode (tip diameter 4-6 $\mu \mathrm{m}$ ) filled with $150 \mathrm{~mm} \mathrm{NaCl}$ was driven into the culture with a hydraulic micromanipulator (WR60; U.S. Narishige, Sea Cliff, NY). A bipolar [ $90 \%$ platinum $/ 10 \%$ iridium twisted Teflon insulated wire (125 $\mu \mathrm{m}$ diameter; number 7780, A-M Systems; Everett, WA)] stimulating electrode was placed on top of the DG immediately inside the genu. A $1 \mathrm{M} \mathrm{KCl}$ agar bridge ground electrode was placed outside the insert in the perfusate. Stimulating pulses were $200 \mu \mathrm{sec}$ in duration and 20-100 V. HOTCs with evoked CA3 field potentials of 2 $\mathrm{mV}$ or less were not used. To enhance the interstitial DC signal, we gently "wicked" the recording solution off the surface of the insert next to HOTCs, using cotton-tipped applicators. To prevent dehydration, we then immediately covered the HOTCs with a layer of light mineral oil. This procedure enhanced the interstitial DC field potential signals by two- to threefold. HOTCs were allowed to equilibrate with perfusion beneath the insert for $30 \mathrm{~min}$ before experimental procedures.

Interstitial DC signals were monitored via an A-1 Axoprobe amplifier system (Axon Instruments, Foster City, CA), digitized with a 1200 series Digidata system (Axon Instruments), and processed with Axoscope software (version 1.1; Axon Instruments). Separate 486 AST computers (AST Research, Irvine, CA) were used to acquire fast and slow signals. Fast evoked signals were sampled every $100 \mu \mathrm{sec}$; slow potential recordings were sampled every $0.1-5 \mathrm{msec}$. For propagation velocity measurements a microelectrode array was created, which consisted of three glass microelectrodes glued so that their tips were $100 \mu \mathrm{m}$ apart in the horizontal plane. Field potential and slow potential records were analyzed with Axoscope software. All field potential figures and slow potential figures were composed with Origin (version 5.0; Microcal Software, Northampton, MA) and CorelDraw software (version 5.0; Corel, Ontario, Canada). Field potential records were smoothed by a SavitzkyGolay smoothing filter@13 pts in Origin.

Spreading depression induction. To initiate SD, we switched the recording solution to a modified Ringer's solution in which $\mathrm{NaCl}$ was replaced with a millimolar equivalent of NaAc, pH 7.60 (Bureś et al., 1974). In addition, NaAc-Ringer's contained $25 \mu \mathrm{M}$ ISO. This modified Ringer's was pulsed on for 90-120 sec, and a SD episode was initiated with a single pulse from the bipolar stimulus electrode placed in the DG immediately after the perfusate was switched back to normal Ringer's. SD episodes were induced every $10-15$ min to simulate SD induction in in vivo preparations in neocortex (Kraig et al., 1991) and hippocampus (Kraig and Kunkler, 1997). Using this interval between SD events, we could use a single preparation for 8-10 hr. Experiments were stopped by choice, not from deterioration of the ability of an HOTC to sustain SD. Occasionally, two to three pulses of modified Ringer's were needed initially to induce SD.

SD propagation velocities were calculated with three-microelectrode array recordings. First, for all electrode recordings, the DC deflection that coincided with the start of SD was defined as the slight positive turn in the wave that followed the initial, sharply negative spike (i.e., point 0 , Fig. 6). Second, the amplitude of this point was subtracted from peak amplitude reached during SD. Third, this relative change in DC potential was multiplied by 0.75 . Finally, the time points along the SD wave that corresponded to the 75th percentile of SD DC deflection were compared among the three traces, and the velocities between microelectrodes (100 $\mu \mathrm{m}$ apart) were determined.

For experiments that used heptanol, a 1 M stock solution of 1-heptanol (Sigma, St Louis, MO) in pure ethanol was prepared fresh daily and diluted into Ringer's with sonification immediately before use (Largo et al., 1997). Final concentrations ranged from 0.75 to $3 \mathrm{~mm}$. HOTCs were incubated for $30 \mathrm{~min}$ in the heptanol-Ringer's solution before the initiation of SD. Control data were collected first in normal Ringer's, followed by exposure to Ringer's containing only vehicle (i.e., ethanol), and then in Ringer's containing heptanol. A 20 min washout followed each concentration of heptanol, during which field potentials and SD were evoked to ensure tissue viability.

Image acquisition. Fluorescence was elicited by excitation with a $100 \mathrm{~W}$ mercury vapor lamp that used a standard fluorescein filter set. Electrical power for the mercury lamp was stabilized with a Topaz Escort micropower conditioner (Square D, Costa Mesa, CA). HOTCs were photographed $(256 \times 256$ pixels $)$ by a 12-bit cooled, charge-coupled camera (CH250; Photometrics, Tucson, AZ). The camera was run under a Windows (3.1) environment on a 486-DX50 AST computer (AST Research) with PMIS software (version 3.0; Photometrics). Electronic images were stored on a Pinnacle Micro optical drive (Sierra $1.3 \mathrm{~GB}$; Pinnacle Micro, Irvine, CA). Images were acquired every $1.2 \mathrm{sec}$ with either a 10 or $25 \times$ objective. To diminish the possibility of phototoxicity, we used a computer-controlled Uniblitz shutter (Vincent Associates, Rochester, NY) to reduce exposure times of cultures to $\leq 100 \mathrm{msec} /$ photograph. The PMIS shutter output signal also was displayed on the slow potential record so that image acquisition could be correlated precisely with DC signals. Bright-field images were acquired with a 540/40 bandpass filter (Chroma Technology, Brattleboro, VT) to confirm HOTC pyramidal cell layer morphology and microelectrode tip position. Power to all electronic equipment was stabilized with an uninterruptible power system (MUPSA-1000; Philtek Power, Blaine, WA).

Image processing and analysis. Computer-based image analysis software, Image Pro Plus (version 1.3; Media Cybernectics, Silver Springs, $\mathrm{MD}$ ), was used for the analysis of $\mathrm{Ca}^{2+}$ images. For Figure 5, images were corrected by using a background reference image, which was sharpened by using a high Gaussian filter $(7 \times 7$ pixel matrix at $50 \%$ strength and one pass), and pseudocolored. The pseudocolor palette was created in Image Pro Plus and consisted of 128 colors over a $0-255$ range. For the SD composite image shown in Figure 6, individual images represent a change in fluorescence over baseline $\left(\Delta F / F_{\mathrm{o}}\right)$, with the fluorescent level under normal conditions (immediately before SD initiation) serving as baseline $\left(F_{\mathrm{o}}\right)$. The images were background-corrected by using a reference file, which consisted of averaging three images that preceded the images of interest. Then the corrected images were equalized linearly, filtered with a low-pass filter to reduce high frequency noise $(3 \times 3$ pixel matrix, at $50 \%$ strength and one pass), and pseudocolored with the same palette as that shown in Figure 5.

Analyses of normal $\mathrm{Ca}^{2+}$ fluorescent intensity fluctuations were conducted by outlining an area of interest (AOI) around individual cells and applying the AOI to subsequent images (with Image Pro software). Intensity values from each AOI were transferred to a spread sheet (Microsoft Excel version 97; Microsoft, Redmond, WA) for statistical analyses. $\mathrm{Ca}^{2+}$ propagation velocities from the SD experiments were determined by measuring the position of the leading edge of the $\mathrm{Ca}^{2+}$ fluorescence increase in successive images and calculating the $\Delta$ position $/ \Delta$ time.

Preparation of illustrations. The depth profile bright-field and corresponding reference images were acquired as 12-bit images $(1024 \times 1024$ pixels) with PMIS software, then converted to 8-bit images of analogous size, and background-corrected in Image Pro Plus. The image brightness 

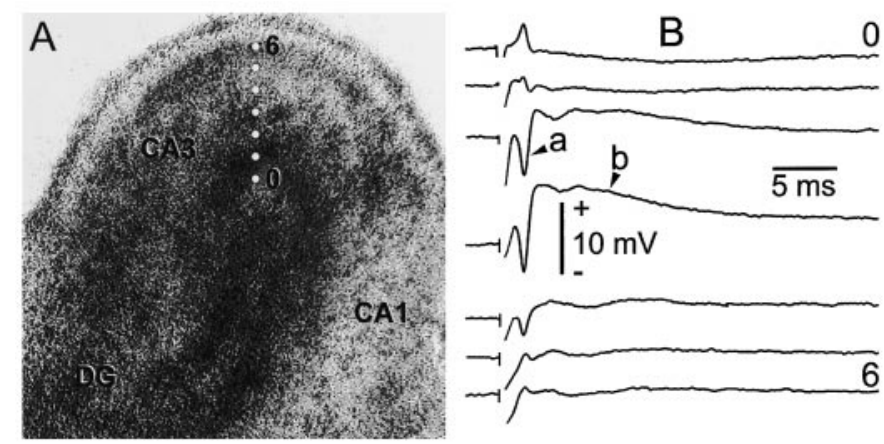

Figure 1. Evoked field potentials from the CA3 pyramidal cell layer. A, Low-power phase-contrast micrograph of a HOTC maintained in vitro for $25 \mathrm{~d}$. The image shown is $1.9 \mathrm{~mm}$ wide. A bipolar stimulating electrode was placed in the hilus of the dentate gyrus $(D G)$ for activation of mossy fiber afferents to CA3 pyramidal cells $(C A 3)$. The CA1 pyramidal cell area $(C A 1)$ is shown to the right. White dots in the CA3 area are $100 \mu \mathrm{m}$ apart, beginning at 0 and ending at 6 (e.g., total distance of $600 \mu \mathrm{m}$ ) perpendicular to the CA3 pyramidal cell layer, and represent electrode recording sites. $B$, Traces represent corresponding evoked field potentials recorded from the outer edge of the culture $(0)$ to $600 \mu \mathrm{m}$ into the culture (6). Field potentials were evoked with a $200 \mu \mathrm{sec}, 50 \mathrm{~V}$ stimulus. DC records show the typical population spike $(a)$ from pyramidal cell action potentials and the slower, large fEPSP of pyramidal cells $(b)$ triggered from pyramidal cell activation. These potential changes are most evident in the third and fourth traces at 200 and $300 \mu \mathrm{m}$, respectively, from the outer edge of the HOTC throughout the pyramidal cell layer area where the so-called inverted fEPSP (i.e., synaptic current source) is maximal. Notice that these potentials reverse as the electrode is moved out of this active area (e.g., traces 0 and 2 for the population spike and traces 5 and 6 for the fEPSP). Time and amplitude calibrations are shown. These CA3 field potentials parallel their counterparts within the rodent hippocampus in vivo.

was reduced and contrast was increased by applying brightness, contrast, and $\gamma$ function values of 35, 64, and 1.0 and applying a high Gaussian filter $(7 \times 7$ pixel matrix at $50 \%$ strength and one pass $)$. Images then were converted to RGB files in Adobe Photoshop (version 4.0; San Jose, CA); the color balance was adjusted (100\% red for shadow, medium, highlights), filtered (unsharp mask, 100\%, 2.0 pixel matrix), and adjusted for brightness $(+40)$ and contrast $(+20)$.

Individual images shown in Figures 5 and 6 were "screen-captured" from Image Pro Plus, and composites were created in Adobe Photoshop. Final images in all instances were printed by using a dye sublimination printer (XKT-7720; Eastman Kodak, Rochester, NY).

\section{RESULTS}

\section{Electrophysiological behavior of HOTC}

The general histological organization of HOTCs (Fig. 1A) is consistent with previous reports of HOTCs (Zimmer and Gähwiler, 1984; Frotscher and Gähwiler, 1988). The HOTC shown is from a culture maintained in vitro for $25 \mathrm{~d}$. HOTCs used in this study were maintained in vitro for $21-35 \mathrm{~d}$ to help ensure that synaptic activity had reached a plateau before experimental manipulations (Buchs et al., 1993; Muller et al., 1993; Bahr, 1995). All cultures showed distinguishable CA1, CA3, and DG subfields. The CA3 pyramidal cell layer maintained a compact layer similar to that seen in vivo. In contrast to that seen in vivo, the CA1 pyramidal cells spread out to form a loosely defined layer (Kunkler and Kraig, 1997a). In addition, the infrapyramidal limb of the DG frequently was diminished in width (Zimmer and Gähwiler, 1984; Kunkler and Kraig, 1997a), yet overall the cytoarchitectural organization of HOTCs was comparable to that seen in vivo.

Evoked synaptic behavior of the CA3 subfield was also similar to that found in vivo and in situ (Fig. 1B). Hippocampal mossy

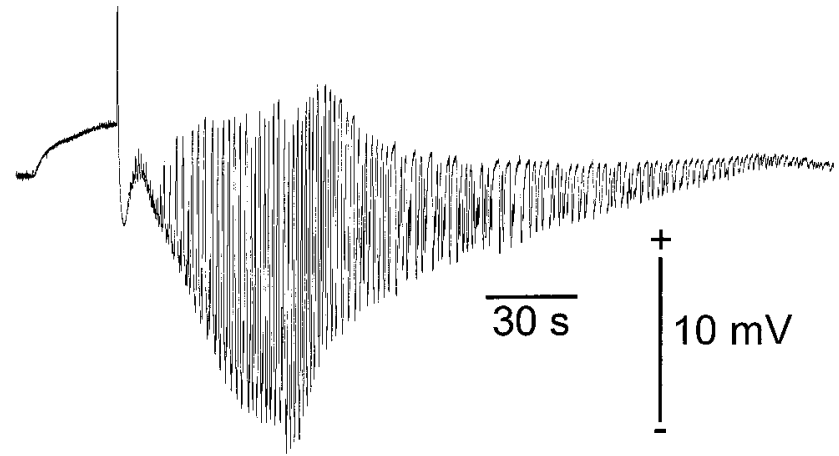

Figure 2. CA3 pyramidal cell layer electrographic seizure. HOTCs showed spontaneous electrical activity that could include electrographic seizures. The record shown is from a microelectrode placed among the basilar dendrites of the CA3 pyramidal cell layer. Shortly after exposure to NaAc-Ringer's, the interstitial DC potential swung millivolts more positive. After $45 \mathrm{sec}$, DC potential swung quickly positive and then more slowly negative. The latter culminated in seizure activity, followed by typical sawtooth activity that initially increased and then progressively decreased in size. Here the HOTC was exposed to NaAc-Ringer's for a total of $75 \mathrm{sec}$. Increasing Ringer's $\mathrm{Ca}^{2+}$ concentration from 1.25 to 2.5 $\mathrm{mm}$ promptly eliminated any spontaneous seizure activity and any that occurred from exposure to NaAc-Ringer's.

fibers arise from DG granule cells and terminate on CA3 pyramidal cells in vivo (Lorente de Nó, 1934; Hamlyn, 1962; Blackstad et al., 1970; Ramon y Cajál, 1995). Similar synaptic connections from the DG to the CA3 pyramidal cells exist within HOTCs (Zimmer and Gähwiler, 1984). Accordingly, bipolar electrical stimulation of the DG may be expected to show evoked field potentials within HOTCs that are similar to those seen in vivo. Field potential recordings (Fig. $1 B$ ) of CA3 pyramidal cell responses to DG stimulation confirmed this. With sufficient stimulation of the mossy fiber afferents, CA3 pyramidal cells began to fire action potentials noted in the interstitial space as a population spike $(a$, Fig. $1 B)$. This was seen during the longer-lasting field EPSP (fEPSP) ( $b$, Fig. $1 B$ ) that was maximally inverted (i.e., moves in the positive direction) at the pyramidal cell layer (trace 4 , Fig. $1 B$ ), where synaptic currents from excitatory dendritic synapses flow from pyramidal cells nearer the cell body (Andersen et al., 1971a,b; Martin, 1983; Alger et al., 1984). Stimulus strength was increased so that the mossy fiber presynaptic volley that otherwise would have been evident (i.e., at $a$, Fig. $1 B$ ) was, instead, overshadowed by the pyramidal cell population spike (most evident in traces 3 and 4 , Fig. $1 B$ ). Field potentials commonly were recorded for SD experiments at the CA3 pyramidal cell layer. To prevent possible induction of synaptic facilitation or depression (Malenka, 1994), we evoked field potentials at a rate of $0.5 \mathrm{~Hz}$ for no more than 2-3 min every $10-15 \mathrm{~min}$. In most experiments a single field potential was evoked to verify microelectrode placement and the physiological status of the HOTC before the induction of each SD.

Electrographic seizures could be induced in HOTCs (Fig. 2). Spontaneous fast electrical activity often was seen when DC potential microelectrodes were advanced into the interstitial space of HOTCs. Such spontaneous electrical activity could be enhanced to include electrographic seizures by, for example, a single bipolar electrical stimulus at the hilus. Others have found similar electrophysiological behavior within HOTCs (Fowler et al., 1986). Ideally, SD can be studied best when evoked by predetermined stimuli, such as bipolar stimulation in the hilus. However, SD will not pass through gray matter areas that are hyper- 
excitable (i.e., are experiencing or recently have experienced electrographic seizures) (Bureś et al., 1975; Koroleva and Bureś, 1979, 1980). Electrographic seizures within HOTCs also prevented SD.

The occurrence of electrographic seizures usually was prevented by the addition of ISO, a $\beta$-adrenergic agonist, along with raising $\mathrm{Ca}^{2+}$ from 1.25 to $2.5 \mathrm{~mm}$ in all Ringer's solutions. This effect of ISO might seem paradoxical, because ISO increases pyramidal cell excitability. For example, ISO increases population spike amplitude in adult CA1 pyramidal cells (Mueller et al., 1981; Dunwiddie et al., 1992) without affecting the fEPSP (Heginbotham and Dunwiddie, 1991). ISO affected HOTCs in this manner. In addition, ISO depolarizes and increases the input resistance of CA3-affected pyramidal cells in immature hippocampal slices as young as postnatal day 7 (Moudy and Schwartzkroin, 1992). However, ISO also increases gap junctional connectivity among astrocytes (Giaume et al., 1991). Thus, the ability of ISO to enhance pyramidal cell excitability and yet decrease electrographic seizures may be attributable, at least in part, to direct effects of this $\beta$-adrenergic agonist on astrocytic gap junctional connections, which could increase the dispersal of $\mathrm{K}^{+}$ via increased spatial buffering (Newman, 1995). Nonetheless, despite the improved electrophysiological function after the addition of ISO to the normal Ringer's solution that was bathing HOTCs, SD still could not be induced by bipolar recurrent electrical stimulation in the hilus.

\section{Induction of SD in HOTCs}

SD could be induced by hilar bipolar electrical stimulation when $\mathrm{Cl}^{-}$in the Ringer's solution was replaced by other anions (Bureś et al., 1974). $\mathrm{Cl}^{-}$was reduced by (1) removing $\mathrm{NaCl}(124 \mathrm{~mm})$ from the Ringer's solution, (2) replacing $124 \mathrm{~mm} \mathrm{NaCl}$ with an isosmotic amount of sucrose, (3) replacing $124 \mathrm{~mm} \mathrm{NaCl}$ with an equimolar amount of sodium propionate or (4) sodium acetate (NaAc) (Bureś et al., 1974). At least three different HOTCs were used for each Ringer's solution above, and the cultures were exposed/stimulated at least 10 times. Each of these Ringer's solutions provided a sufficient "conditioning" change to induce SD after a single bipolar electrical stimulus in the hilus. However, substitution with NaAc was the most consistent conditioning change. Therefore, it was used to induce SD in all experiments. Prolonged exposure of HOTCs to NaAc-Ringer's alone would induce electrographic seizures. However, with the addition of ISO and raised $\mathrm{Ca}^{2+}$ to all Ringer's solutions, coupled to transient $(90-120 \mathrm{sec})$ exposure of HOTCs to NaAc-Ringer's solution, seizure activity was rarely seen. Finally, SD was induced consistently ( $n>100$ ) only when Ringer's solution above the HOTCs was removed and replaced with mineral oil or moist air. Only rarely would exposure to NaAc-Ringer's successfully induce SD in submerged HOTCs. None of the other anionsubstituted Ringer's solutions above were a sufficient conditioning solution for SD when HOTCs were submerged.

Two of the three fundamental electrophysiological characteristics of SD are shown in Figure 3. The first is the slow interstitial DC potential change of SD (thick record, Fig. 3). Exposure to NaAc-Ringer's always produced a small positive deflection in the interstitial DC potential. After 90-120 sec the Ringer's solution was returned to normal, and a single bipolar electrical stimulus was delivered quickly to the hilus. This invariably produced SD, as evidenced by a dramatic negative shift in the interstitial DC potential of $30-50 \mathrm{mV}$ (points $2-4$ of slow DC potential record, Fig. 3) (Leão, 1944). When the DC shift of SD began to recover

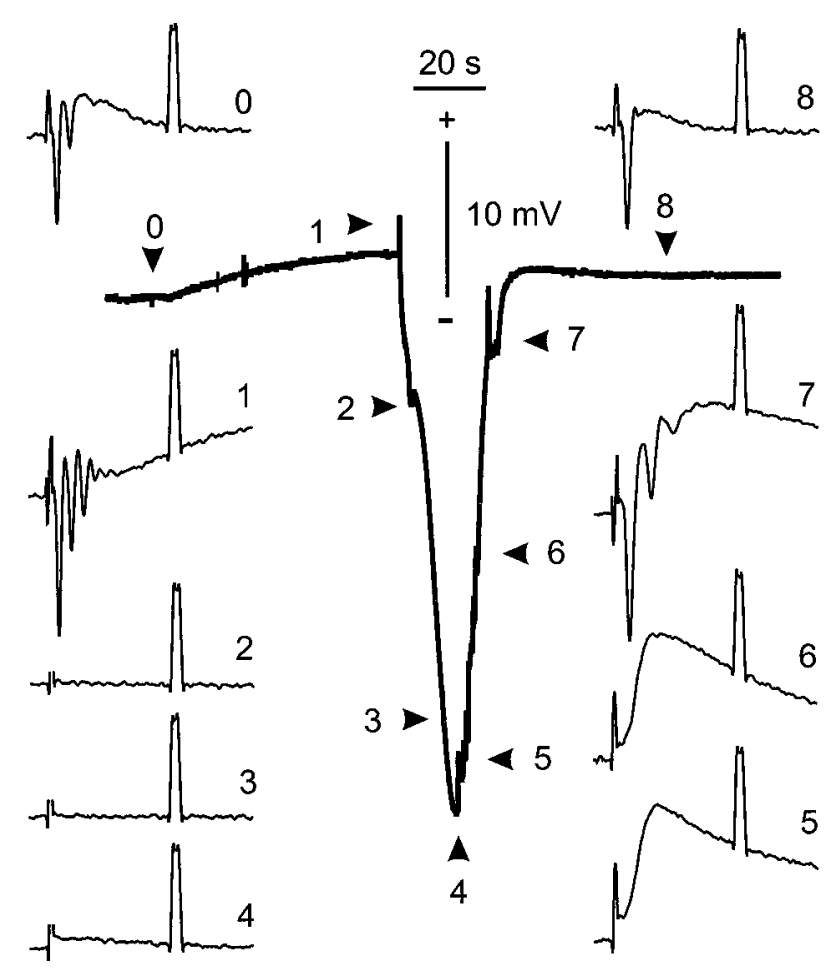

Figure 3. Evoked field potential and interstitial DC potential changes associated with SD. Classical electrophysiological evidence for SD consists of a slowly propagating, large negative DC potential in the interstitial space associated with a transient loss of spontaneous and/or evoked neuronal activity. The association of the DC potential (thick record) with the change in evoked field potentials (thin traces) during SD in a HOTC is shown. This event was one of 40 such SD episodes induced every 10-15 min from the same culture over an $8 \mathrm{hr}$ period. Field potentials were evoked at specific time points $(0-8)$ shown on the DC record. A calibration pulse $(10 \mathrm{mV}, 2 \mathrm{msec})$ is shown toward the latter half of each field potential trace. The interstitial DC calibration time and voltage bars are shown. With NaAc exposure, the interstitial slow DC potential (large thick line) initially shifted more positive. Then with the evoked pulse from the hilus (1), interstitial DC potential briefly became more positive and then swung negative, reaching a peak (2) approximately $-10 \mathrm{mV}$ from baseline. Finally, SD occurred. This was evidenced by a massive shift in DC potential that reached $-45 \mathrm{mV}$ from baseline $(0)$ in this example before returning to baseline. Further support that this DC change was SD came from alterations in the field potentials. Successive SDs $(n=12)$ could make pyramidal cells hyperexcitable. For example, two population spikes are seen (trace 0 ) before the associated slower, large fEPSP. Then, with exposure to NaAc-Ringer's, evoked potentials became even more excitable (trace 1), showing multiple population spikes before becoming completely absent (traces 2-4) as the DC potential swung to its most negative extreme. Recovery frequently was associated with epileptiform activity, as in this example (points 5-7 along the slow DC record). In addition, pyramidal cells initially showed an exaggerated fEPSP (traces 5 and 6 ) and then multiple population spikes (trace 7). Shortly after SD, pyramidal cell fEPSPs were reduced slightly (compare trace 8 with 0 ).

toward the baseline, spontaneous epileptiform activity commonly was seen (points 5-7 along DC potential record, Fig. 3). This has been observed in hippocampal brain slices derived from adult (Snow et al., 1983) and immature (Psarropoulou and Avoli, 1993) rats. Notice that the bipolar stimulus to trigger SD also is associated with a uniquely large DC negative shift (between points 1 and 2 of the slow DC potential record, Fig. 3). This initial negative deflection of $\sim 10 \mathrm{mV}$ occurred synchronously throughout the HOTC, as evidenced by three microelectrodes separated by $100 \mu \mathrm{m}$ (Fig. 4) and placed variably throughout HOTCs. Furthermore, the initial DC negative deflection was never evident 


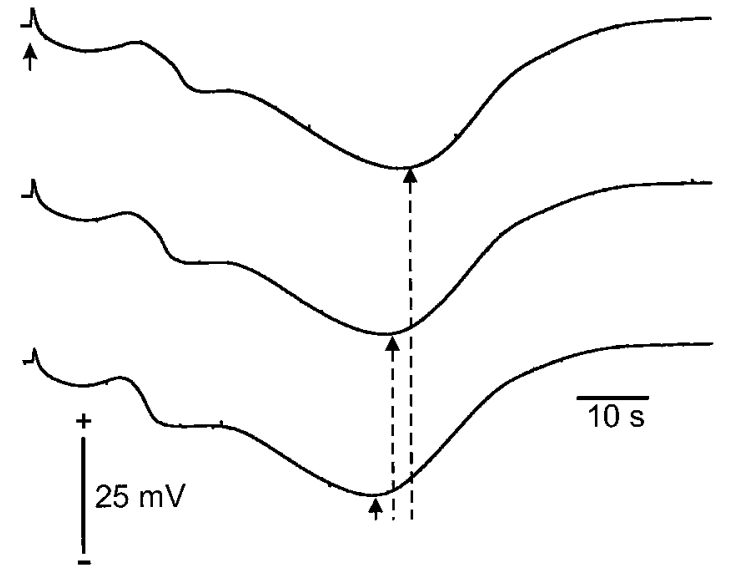

Figure 4. Propagation of interstitial DC potential associated with SD. Three microelectrodes were placed in a row along the CA3 pyramidal cell layer to demonstrate the third classical electrophysiological characteristic of SD, that of interstitial DC potential propagation. In the example shown, the center trace is from a microelectrode placed at the apex of the CA3 pyramidal cell layer where the hilar-evoked CA3 field potential was maximized. Other microelectrodes were $100 \mu \mathrm{m}$ to either side of the center microelectrode. The bottom trace is from the microelectrode that was closer to the CA1 area. The top trace is from the microelectrode that was closer to the dentate gyrus. The arrowhead indicates the time of triggering evoked field potential used to initiate SD. Dotted lines with arrows show peak DC potential change from SD at each recording zone. Propagation velocity between the bottom and middle traces equals 12.1 $\mathrm{mm} / \mathrm{min}$ and between middle and top traces equals $6.1 \mathrm{~mm} / \mathrm{min}$. Propagation velocities overall averaged $5.47 \mathrm{~mm} / \mathrm{min} \pm 0.47(n=15)$, based on recordings compiled from nine HOTCs. Time and voltage calibrations are shown.

from bipolar stimulation without exposure to NaAc-Ringer's (data not shown). The DC potential change from the bipolar stimulus also was associated with a fast propagating $\mathrm{Ca}^{2+}$ wave (see below). These fast $\mathrm{Ca}^{2+}$ waves were never seen with bipolar stimuli in HOTCs exposed to normal Ringer's solution.

The second hallmark of SD, transient cessation of evoked electrical activity (thin traces 2-4, Fig. 3) (Leão, 1944), was also evident during the negative, slow DC potential change. CA3 pyramidal cell responses could become hyperactive after successive SDs $(n=12)$. This was evident before SD (fast DC potential trace 0, Fig. 3) in which two population spikes are seen before exposure to NaAc-Ringer's. The latter further increased excitability (fast DC potential trace 1, Fig. 3) so that multiple population spikes occurred along with a dramatically widened fEPSP. Then, as expected with the onset of SD (fast DC potential trace 2, Fig. 3) until the peak slow DC change (fast DC potential traces 3 and 4, Fig. 3), no evoked field potentials were seen. With recovery (fast DC potential traces 5-8, Fig. 3), pyramidal evoked activity progressively returned. Initially, only an exaggerated fEPSP could be seen (fast DC potential traces 5 and 6, Fig. 3). This quickly was followed by epileptiform activity (as noted above in the slow DC potential record) and the production of multiple population spikes by bipolar stimulation (fast DC potential trace 7, Fig. 3). Finally, the fEPSP was reduced immediately after SD (compare fast DC potential traces 0 and 8 , Fig. 3 ).

The third classical electrophysiological change of SD, slow propagation of a large negative interstitial DC potential (Leão, 1944), is shown in Figure 4. DC propagation velocities averaged $5.47 \pm 0.47 \mathrm{~mm} / \mathrm{min}(n=15)$, a speed similar to values found in vivo (Leão, 1944; Bureś et al., 1974) and in the in vitro hippocam- pal brain slice preparation (Snow et al., 1983; Psarropoulou and Avoli, 1993).

\section{Intercellular $\mathrm{Ca}^{2+}$ waves and SD}

Glutamate can be an effective stimulus to evoke SD (Bureś et al., 1974). Furthermore, it evokes propagating intracellular and intercellular $\mathrm{Ca}^{2+}$ waves in HOTCs (Dani et al., 1992) (Fig. 5). HOTCs are surrounded by a rim of glial (astrocytes and microglia) cells (Kunkler and Kraig, 1997a) that can be used as a mixed glial cell preparation. $\mathrm{Ca}^{2+}$ waves from glutamate exposure were noted in both of these areas. In the mixed glial cell rim around the HOTCs, $\mathrm{Ca}^{2+}$ waves could be seen in individual cells (Fig. 5). Glutamate $(100 \mu \mathrm{M})$ evoked oscillations within single cells as well as rapidly propagating waves of $\mathrm{Ca}^{2+}$ between cells $(n=10)$, as has been reported previously in primary astrocytic cultures (Cornell-Bell et al., 1990; Charles et al., 1991, 1992; Cornell-Bell and Finkbeiner, 1991; Finkbeiner, 1992; Enkvist and McCarthy, 1994). $\mathrm{Ca}^{2+}$ waves also were seen within HOTCs during exposure to elevated glutamate. These changes have been noted previously within HOTCs (Dani et al., 1992) and within the in situ rat retina (Newman and Zahs, 1997). However, electrophysiological changes of SD were never seen from glutamate exposure $(n=30)$. Thus, glutamate-evoked $\mathrm{Ca}^{2+}$ waves can occur without electrophysiological evidence of SD.

Electrophysiological changes of $\mathrm{SD}$, on the other hand, do occur with $\mathrm{Ca}^{2+}$ waves (Fig. 6). Transient exposure to NaAcRinger's was necessary to elicit SD in HOTCs by a single bipolar stimulus to the hilar area of the DG. SD always $(n=6)$ occurred with two distinct $\mathrm{Ca}^{2+}$ waves. The first occurred within 1-2 sec of the synchronous DC deflection recorded in the pyramidal cell layer from bipolar electrical stimulation. Furthermore, it propagated $>100 \mu \mathrm{m} / \mathrm{sec}$ in the oriens layer and originated either in CA1 or CA3. Figure 6 shows this wave beginning in CA1/CA2 (image 1, Fig. 6) and rapidly propagating toward the hilus along the oriens layer (image 2, Fig. 6). The second wave propagated mostly perpendicular to the pyramidal cell layer from a nidus in CA3 (or less often CA1) (images 3-6, Fig. 6). In addition, this second wave propagated at the speed of SD $(4.0 \pm 0.2 \mathrm{~mm} / \mathrm{min}$; $n=6)$. However, the peak change in $\mathrm{Ca}^{2+}$ of this second wave always preceded the peak interstitial DC change of SD by a significant ( $p<0.001$ tested by an unpaired Student's $t$ test; $n=$ 6) margin of $6-16 \mathrm{sec}$.

To explore further whether $\mathrm{Ca}^{2+}$ waves are essential for SD initiation and propagation, we exposed HOTCs to heptanol (data not shown). Heptanol reversibly uncouples gap junctions (Spray and Bennett, 1985; Bastiaanse et al., 1993). Furthermore, it can stop the propagation of intercellular $\mathrm{Ca}^{2+}$ waves as well as the initiation of SD (Martins-Ferreira and Ribeiro, 1995; Nedergaard et al., 1995). DC potentials were recorded in the CA1 and CA3 pyramidal cell layers after HOTCs were loaded with Fluo-3. Ethanol, the vehicle for heptanol, did not affect evoked field potentials or SD and associated $\mathrm{Ca}^{2+}$ waves $(n=5)$. Heptanol in high concentrations $(3 \mathrm{~mm})$ reversibly abolished field potentials $(n=3)$ as well as $\mathrm{Ca}^{2+}$ waves and SD. However, because an evoked field potential was needed to initiate $\mathrm{SD}$, the dose of heptanol was titrated downward to discover if $\mathrm{Ca}^{2+}$ waves could be separated from SD. The results suggest that such a separation cannot be accomplished. First, without exposure to heptanol, electrophysiological changes of SD occasionally did not propagate from CA3 to CA1 (and vice versa). Under these cases, $\mathrm{Ca}^{2+}$ waves were not seen in those areas that did not show DC changes of SD $(n=7)$. Then in other experiments, exposure to lower 

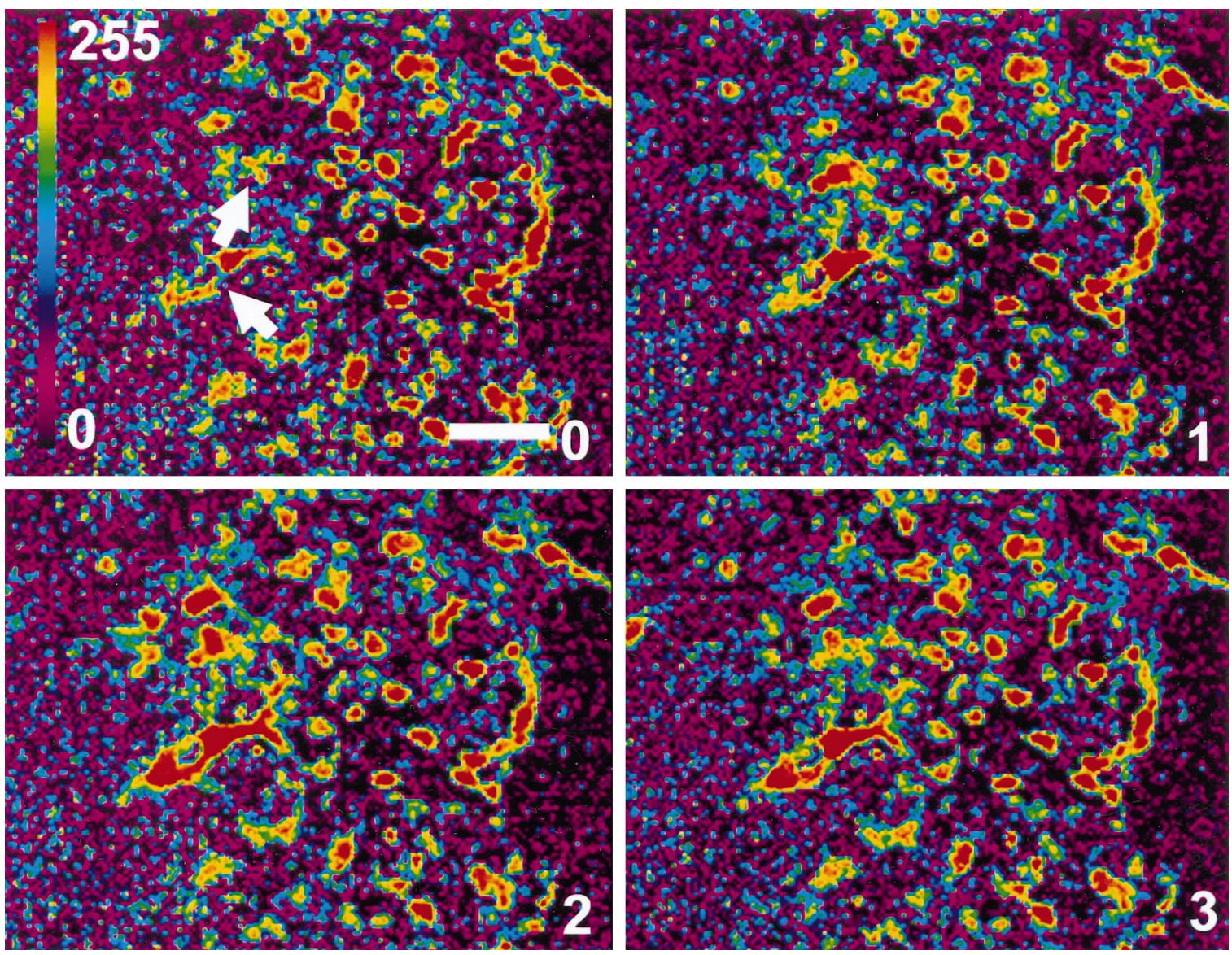

Figure 5. Astrocytic $\mathrm{Ca}^{2+}$ fluctuations at HOTC edge. HOTCs are surrounded by a rim of microglial cells and astrocytes that can be used as a mixed glial cell preparation. Here a HOTC (maintained in vitro for $45 \mathrm{~d}$ ) was preloaded with the intracellular calcium-sensitive dye Fluo-3. Glial cells at the edge of the HOTC, initially identified via phase-contrast microscopy, were examined with time-lapse digital photo microscopy (1.2 sec/image) during exposure to $100 \mu \mathrm{M}$ glutamate in normal Ringer's solution. Images were pseudocolored to emphasize changes in fluorescence intensity that correspond to changes in intracellular calcium. The intensity scale extends from 0 to 255 (i.e., low to high $\mathrm{Ca}^{2+}$ concentration) and is shown in image 0 . Repeated exposures to glutamate caused a progressive rise in fluorescence intensity that is evident in the images shown. Arrows emphasize particular spontaneous $\mathrm{Ca}^{2+}$ changes. The top arrow points to astrocytes that show a transient rise and fall of cellular $\mathrm{Ca}^{2+}$ concentration. The bottom arrow points to cells that undergo propagation of a rise in intracellular $\mathrm{Ca}^{2+}$ concentration between two adjacent astrocytes. Image 1 shows a rise in $\mathrm{Ca}^{2+}$ from that seen in image 0 . In addition, this rise propagates to the distal aspects of the right-hand cell and to the left-hand cell (image 2). Ca ${ }^{2+}$ concentration is beginning to fall in distal aspects of both cells in image 3. Cells were presumed to be astrocytes by using morphological criteria in phase-contrast microscopy. These cells showed $90-100 \%$ fluctuations in fluorescent intensity between images. The propagation of the $\mathrm{Ca}^{2+}$ signal changes that appeared both within (top arrowhead) and between cells (bottom arrowhead) is consistent with changes reported from primary cultures of astrocytes. Scale bar, $10 \mu \mathrm{m}$.

levels of heptanol (0-1.5 mM) often extinguished $\mathrm{Ca}^{2+}$ waves and SD despite preserved evoked field potentials in both CA3 and CA1 $(n=9$ HOTCs and 26 SDs $)$. For example, SD and $\mathrm{Ca}^{2+}$ waves were seen in 11 of 13 trials $(85 \%)$ at $0.75 \mathrm{~mm}$ heptanol, 2 of 4 trials $(50 \%)$ at $1.0 \mathrm{~mm}$ heptanol, 2 of 9 trials $(22 \%)$ at $1.5 \mathrm{~mm}$ heptanol, and 0 of 3 trials at $3.0 \mathrm{~mm}$ heptanol. Thus, two distinct types of $\mathrm{Ca}^{2+}$ waves precede SD and appear to be essential for the initiation and propagation of this phenomenon.

\section{DISCUSSION}

$\mathrm{Ca}^{2+}$ waves in neural cells (Cornell-Bell et al., 1990; Charles et al., 1991, 1992, 1996; Cornell-Bell and Finkbeiner, 1991; Finkbeiner, 1992; Enkvist and McCarthy, 1994) and tissues (Dani et al., 1992; Newman and Zahs, 1997) resemble SD because of their similar propagation velocities, yet the relationship of $\mathrm{Ca}^{+}$ waves to the electrophysiological changes of SD is unknown. Our results show, for the first time, that HOTCs support SD. Furthermore, two distinct $\mathrm{Ca}^{+}$waves travel through HOTCs ahead of the SD electrophysiological changes. The first travels rapidly along the basilar pyramidal cell dendrites, whereas the second travels slowly and mostly perpendicular to the pyramidal cell layer. These findings may be linked to functional changes in gap junctions.

\section{Initiation of SD in HOTCs}

Despite the increased use of HOTCs, SD has not been reported in these cultures. This lack is attributable to at least two facts. First, although acute rodent hippocampal slices easily support SD (Snow et al., 1983; Psarropoulou and Avoli, 1993), HOTCs typically do not. Both preparations lack extrinsic inputs. Furthermore, they both display similar spontaneous and evoked electrophysiological activity. Nonetheless, the tissue volume activated by depolarizing stimuli is less in HOTCs than in acute hippocampal brain slices. HOTCs are $\sim 50-150 \mu \mathrm{m}$ thick (our unpublished observations), whereas acute hippocampal slices are typically 300-400 $\mu \mathrm{m}$ thick (Alger et al., 1984). Thus, DG gyrus bipolar electrical stimulation activates a smaller volume of CA3 pyramidal cells in HOTCs than acute slices. SD initiation requires a 

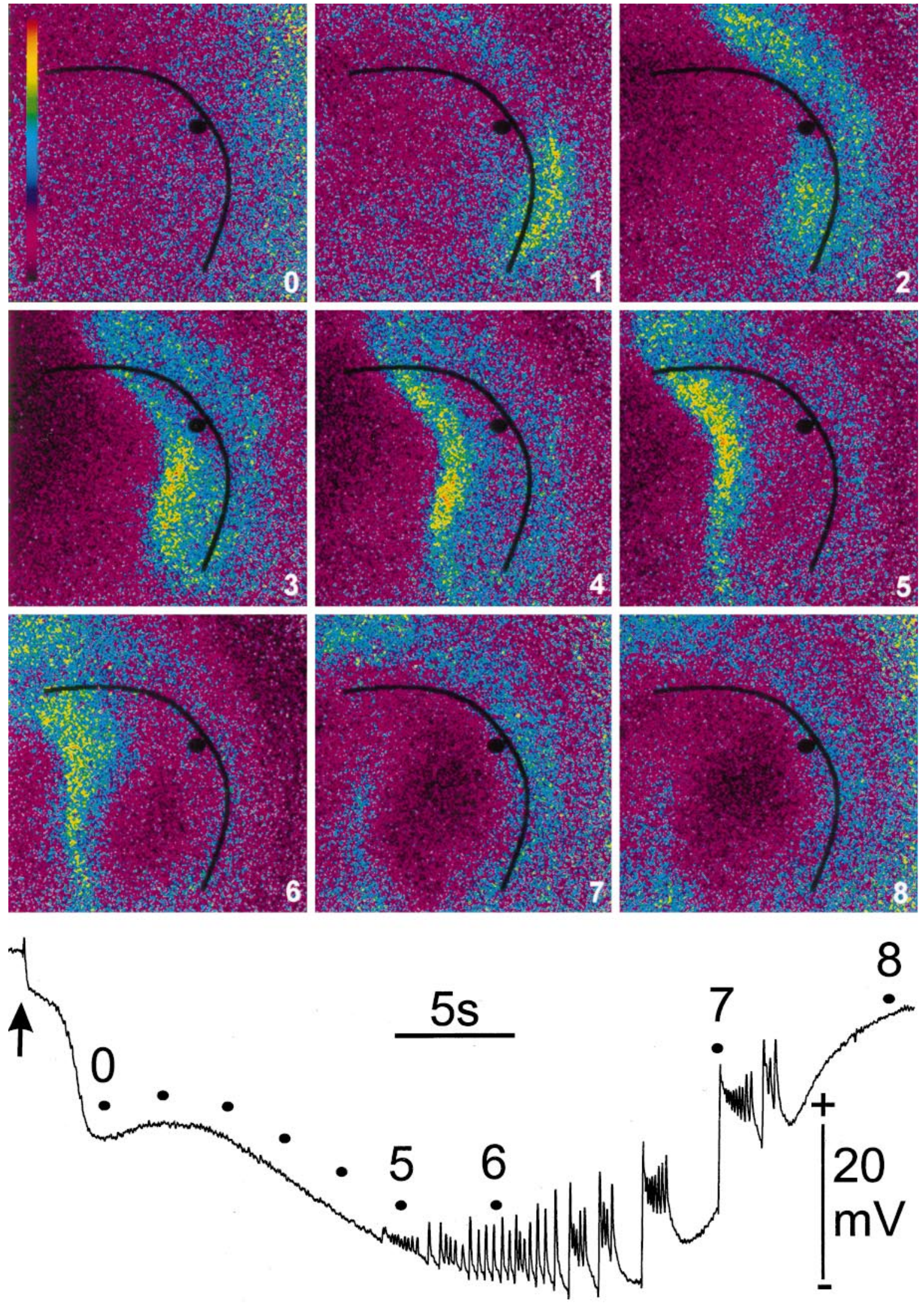

Figure 6. Propagation of intercellular $\mathrm{Ca}^{2+}$ wave associated with SD in HOTC. The classic electrophysiological changes of SD have never been shown to occur with $\mathrm{Ca}_{2+}$ propagating waves. Here interstitial DC potential and intracellular $\mathrm{Ca}^{2+}$ were monitored simultaneously to determine whether $\mathrm{Ca}^{2+}$ waves occurred with SD. A microelectrode was placed in the pyramidal cell layer (black line) in CA3 (black dot) after Fluo-3 was loaded into the HOTC, as described in Figure 5. Changes in fluorescence intensity were pseudocolored on a 0-255 scale, as described in Figure 5. Purple and black indicate low $\mathrm{Ca}^{2+}$, whereas blue, yellow, and red indicate progressively higher calcium concentration. Images were acquired every 1.2 sec, (Figure legend continues.) 
sufficient volume of gray matter to be acutely depolarized (Bureś et al., 1974). Perhaps the volume of CA3 activated by bipolar DG stimulation in HOTCs is simply too low to initiate SD in either CA3 or CA1 under normal conditions. This conclusion is supported by our finding that SD could be initiated very rarely in HOTCs submerged under normal Ringer's superfusion. However, when HOTCs were used in an "interface" chamber where Ringer's exposure was restricted to the bottom surface of the cultures, SD could begin to be initiated by electrical stimulation. This implies that soluble substances released to the interstitial space are essential for SD. Diffusion (Nicholson, 1995) of essential materials away from thin submerged HOTCs might be too rapid to allow for SD initiation. Alternatively, ephaptic interactions between neural cells (Taylor and Dudek, 1984; Faber and Korn, 1989) could be enhanced within HOTCs in an interface chamber, as compared with submerged HOTCs.

A second potential reason why SD has not been reported previously in HOTCs stems from the seemingly convoluted "conditioning" needed to evoke the phenomenon consistently. Our first attempts at inducing SD in HOTCs centered on increasing HOTC excitability by altering Ringer's constituents (our unpublished observations) and were unsuccessful. Raising Ringer's $\mathrm{K}^{+}$ or lowering $\mathrm{Ca}^{2+}$ or $\mathrm{Mg}^{2+}$ only induced spontaneous or evoked seizure activity. Similarly, the addition of glutamate, NMDA, carbachol, or 4-aminopyridine, each of which has excitatory effects, only resulted in seizure activity. Later attempts centered on reducing Ringer's $\mathrm{Cl}^{-}$. This is a well recognized method of altering interstitial fluid to promote the induction of SD (Bureś et al., 1974). The mechanisms responsible for this effect are unknown but may be related to increased excitability (Nicholson and Kraig, 1981; Haglund and Schwartzkroin, 1984). Again, only epileptiform activity occurred when $\mathrm{Cl}^{-}$was replaced with propionate or acetate. Similar results occurred in acute hippocampal slices when Ringer's $\mathrm{Cl}^{-}$was replaced with propionate (Yamamoto and Kawai, 1967). The final, and virtually always successful, method used to induce SD involved transient exposure to NaAc-Ringer's that also contained ISO and raised $\mathrm{Ca}^{2+}$.

\section{$\mathrm{Ca}^{2+}$ waves and SD}

Gap junctions between neurons (Somjen et al., 1992; Herreras et al., 1994; Largo et al., 1997) and astrocytes (Nedergaard et al., 1995) may play important roles in SD initiation and propagation, respectively. Although raised $\mathrm{Ca}^{2+}$ has no direct effect on gap junction, other Ringer's changes (the addition of ISO and the replacement of $\mathrm{Cl}^{-}$by acetate) could increase gap junctional conductances. For example, ISO increases gap junctions between cultured astrocytes (Giaume et al., 1991). Furthermore, transient exposure to NaAc should begin to acidify neural cells (Roos and Boron, 1981). This might be expected to reduce gap junctional conductances (Spray et al., 1981). However, conductance through gap junctions made of connexin 43 and connexin 32, gap junctional proteins found in brain (Giaume and McCarthy, 1996), increases with a reduction in cellular $\mathrm{pH}$. For example, gap junctions formed between pairs of Xenopus laevis oocytes expressing homologous channels for these proteins show an increase in conductance when intracellular $\mathrm{pH}$ is lowered from 7.2 to 6.8 or from 7.2 to 6.3, respectively (Liu et al., 1993).

The magnitude of the interstitial DC potential change from bipolar stimulation (see Fig. 3) supports the notion of increased cellular connectivity during HOTC exposure to NaAc. During normal Ringer's solution exposure the DC deflection from a bipolar stimulus to the DG was not seen in CA3 (i.e., points 0 and 8 of slow DC potential record, Fig. 3) or CA1 (data not shown). However a positive and then a large negative DC deflection of $\sim 10 \mathrm{mV}$ was always seen in CA3 (and CA1) synchronously with the same stimulus during NaAc exposure. The large size of this DC deflection and the distance (i.e., $>1 \mathrm{~mm}$ ) over which it simultaneously was seen implies the existence of a long-distance conductance path along the pyramidal cell layer. This could be attributable to the opening of normally closed neuronal gap junctions between pyramidal cells, as has been suggested for seizures (Perez-Velazquez et al., 1994) and SD (Somjen et al., 1992; Herreras et al., 1994; Largo et al., 1997).

The speed and cytoarchitectural direction of the rapidly propagating $\mathrm{Ca}^{2+}$ wave seen shortly after the start of SD further support the suggestion of increased gap junctional connectivity among pyramidal cells. Neuronal $\mathrm{Ca}^{2+}$ waves travel at $>100$ $\mu \mathrm{m} / \mathrm{sec}$ (Charles et al., 1996), a speed consistent with that seen for the rapidly propagating wave that spreads along the pyramidal cell basilar dendritic layer (see Fig. 6). Furthermore, no cellular elements extend along this layer that otherwise could account for the propagating intercellular $\mathrm{Ca}^{2+}$ wave. Finally heptanol, which uncouples gap junctions (Spray and Bennett, 1985; Bastiaanse et al., 1993), stopped this $\mathrm{Ca}^{2+}$ wave as well as the large $\mathrm{DC}$ deflection associated with bipolar stimulation.

Heptanol also stopped the slower $\mathrm{Ca}^{2+}$ wave and SD itself, as reported by others (Martins-Ferreira and Ribeiro, 1995; Nedergaard et al., 1995). The slowly propagating $\mathrm{Ca}^{2+}$ wave traveled at speeds consistent with similar waves seen among astrocytes (Cornell-Bell et al., 1990; Charles et al., 1991, 1992; Cornell-Bell and Finkbeiner, 1991; Finkbeiner, 1992; Enkvist and McCarthy, 1994). Furthermore, the slower $\mathrm{Ca}^{2+}$ wave spread mostly perpendicular to pyramidal cells but also in all directions from an initial focus. Astrocytes are dispersed ubiquitously throughout the laminae of the HOTC (Kunkler and Kraig, 1997a). Therefore, as suggested by others (Nedergaard, 1994; Nedergaard et al., 1995), it is plausible to propose that this slower $\mathrm{Ca}^{2+}$ wave during SD in HOTCs also relies on gap junctional connections among astrocytes. $\mathrm{A} \mathrm{Ca}^{2+}$ wave that precedes SD

\footnotetext{
with the first six images shown in sequence. After a $90 \mathrm{sec}$ perfusion with NaAc-Ringer's, SD was initiated by a single electrical pulse (200 $\mu$ sec, $50 \mathrm{~V})$ via a bipolar stimulating electrode in the hilus (arrow). No changes from the preceding baseline images in $\mathrm{Ca}^{2+}$ were detectable with either the single electrical pulse (arrow; positive deflection in DC record) or with the subsequent negative shift that immediately followed (image 0 ). The first increase in $\mathrm{Ca}^{2+}$ was observed in the oriens layer at the CA1/CA2 pyramidal cell junction (bottom right of black line; image 1), followed by a rapid propagation through the oriens layer of CA3 toward the hilus (top left of black line; image 2). The second change was a $\mathrm{Ca}^{2+}$ increase that spread similarly into stratum radiatum of CA1/CA2 and rapidly propagated through this layer into CA3 (images 2-5). Besides propagating parallel to the pyramidal cell layer, a third aspect of the $\mathrm{Ca}^{2+}$ changes was a slower propagation of $\mathrm{Ca}^{2+}$ change perpendicular to the pyramidal cell layer (images 3-6) along the apical dendrites. $\mathrm{Ca}^{2+}$ propagation away from the pyramidal cell layer was measured at $4.0 \pm 0.2 \mathrm{~mm} / \mathrm{min}(n=6)$. Only minor fluctuations in Ca ${ }^{2+}$ fluorescence were observed after the SD episode reached its peak amplitude (image 6 ) and as the slow potential trace returned to baseline values (images 7 and 8 ). Note that maximum $\mathrm{Ca}^{2+}$ change at the microelectrode recording site (images 2-3) preceded the maximal change in interstitial DC potential (bottom record) by a few seconds. The DC record was not filtered. As often occurred with repolarization, the HOTC showed spontaneous epileptiform activity (positive-going deflections between points 5 and 8). Time and amplitude calibrations are shown. Image dimensions are $920 \times 920 \mu \mathrm{m}$.
} 
has been noted by others in acute hippocampal brain slices (Basarsky and MacVicar, 1997).

\section{Significance of SD in HOTCs}

The discovery of two distinct $\mathrm{Ca}^{2+}$ waves that precede electrophysiological changes of SD adds further support to the suggestion that changes in neural function precede the regenerative depolarization of SD (Herreras et al., 1994). Somjen and colleagues (Somjen et al., 1992; Herreras et al., 1994; Largo et al., 1997) suggest that SD involves the opening of previously closed neuronal gap junctions. That these waves occur before the regenerative electrophysiological changes of SD suggest they could effect triggering mechanisms within (Post and Silberstein, 1994; Finkbeiner, 1995) and among neural cells (Nedergaard, 1994; Parpura et al., 1994) that are essential for SD. Furthermore, given the diverse and potentially long-lasting effects of cellular $\mathrm{Ca}^{2+}$ changes (Whitfield, 1990; Post and Silberstein, 1994), $\mathrm{Ca}^{2+}$ waves from SD also may trigger mechanisms responsible for temporally remote phenomena, such as $\mathrm{SD}$-induced modulation of ischemic injury.

The discovery of the mechanisms responsible for SD has increased importance because SD is now known to influence ischemic brain injury. When SD precedes ischemia by $<1 \mathrm{~d}$, injury is greater than otherwise would be expected from ischemia alone (Takano et al., 1996). However, when SD occurs $>1$ d before ischemia, injury is reduced from that which otherwise would be seen (Kawahara et al., 1995; Kobayashi et al., 1995; Matsushima et al., 1996). Clarification of the mechanisms responsible for SD could lead to improved insight to the pathogenesis of ischemic brain injury. Furthermore, knowledge of specific mechanisms responsible for SD might reveal how brain injury from ischemia may be mitigated or perhaps even reversed. Currently, the mechanisms by which SD confers this dual effect on ischemic injury are unknown. However, HOTCs may be ideal for studies directed toward such mechanisms, because HOTCs support SD and they can be maintained in vitro for months, where individual cells can be followed in space and time.

\section{REFERENCES}

Alger BE, Dhanjal SS, Dingledine R, Garthwaite J, Henderson G, King GL, Lipton P, North A, Schwartzkroin PA, Sears TA, Segal M, Whittingham TS, Williams J (1984) Appendix: brain slice methods. In: Brain slices (Dingledine R, ed), pp 381-437. New York: Plenum.

Andersen P, Bliss TVP, Skrede KK (1971a) Unit analysis of hippocampal population spikes. Exp Brain Res 13:208-221.

Andersen P, Bliss TVP, Skrede KK (1971b) Lamellar organization of hippocampal excitatory pathways. Exp Brain Res 13:222-238.

Bahr BA (1995) Long-term hippocampal slices: a model system for investigating synaptic mechanisms and pathologic processes. J Neurosci Res 42:294-305.

Basarsky TA, MacVicar BA (1997) Intracellular calcium dynamics during hippocampal spreading depression. Soc Neurosci Abstr 23:1463.

Bastiaanse E, Jongsma H, Van der Laarse A, Takenskwak B (1993) Heptanol-induced decrease in cardiac gap junctional conductance is mediated by a decrease in the fluidity of membranous cholesterol-rich domains. J Membr Biol 136:135-145.

Blackstad TW, Brink K, Hem J, Jeune B (1970) Distribution of hippocampal mossy fibers in the rat. An experimental study with silver impregnation methods. J Comp Neurol 138:433-450.

Buchs P-A, Stoppini L, Muller D (1993) Structural modifications associated with synaptic development in area CA1 of rat hippocampal organotypic cultures. Dev Brain Res 71:81-91.

Bureś J, Bureŝova O, Krřivánek J (1974) The mechanism and applications of Leão's spreading depression of electroencephalographic activity. New York: Academic.

Bureś J, von Schwarzenfeld I, Brozek G (1975) Blockade of cortical spreading depression by picrotoxin foci of paroxysmal activity. Epilepsia 16:111-118.

Charles AC, Merrill JE, Dirksen ER, Sanderson MJ (1991) Intercellular signaling in glial cells: calcium waves and oscillations in response to mechanical stimulation. Neuron 6:983-992.

Charles AC, Naus CCG, Z hu D, Kidder GM, Dirksen ER, Sanderson MJ (1992) Intercellular calcium signaling via gap junctions in glioma cells. J Cell Biol 118:195-201.

Charles AC, Kodali SK, Tyndale RF (1996) Intercellular calcium waves in neurons. Mol Cell Neurosci 7:337-353.

Cornell-Bell AH, Finkbeiner SM (1991) $\mathrm{Ca}^{2+}$ waves in astrocytes. Cell Calcium 12:185-204.

Cornell-Bell AH, Finkbeiner SM, Cooper MS, Smith SJ (1990) Glutamate induces calcium waves in cultured astrocytes: long range glial signaling. Science 247:470-473.

Dani JW, Chernjavsky A, Smith SJ (1992) Neuronal activity triggers calcium waves in hippocampal astrocytic networks. Neuron 8:429-440.

Dunwiddie TV, Taylor M, Heginbotham LR, Procotor WR (1992) Long-term increases in excitability in the CA1 region of rat hippocampus by $\beta$-adrenergic stimulation: possible mediation by cAMP. J Neurosci 12:506-517.

Enkvist MOK, McCarthy KD (1994) Astroglial gap junction communication is decreased by treatment with either glutamate or high $\mathrm{K}^{+}$ concentration. J Neurochem 62:489-495.

Faber DS, Korn H (1989) Electrical field effects: their relevance in central neural networks. Physiol Rev 69:821-863.

Finkbeiner SM (1992) Calcium waves in astrocytes-filling in the gaps. Neuron 8:1101-1108.

Finkbeiner SM (1995) Modulation and control of intracellular calcium. In: Neuroglia (Kettenmann H, Ransom BR, eds), pp 273-288. New York: Oxford.

Fowler J, Bornstein MB, Crain SM (1986) Sustained hyperexcitability elicited by repetitive electric stimulation of organotypic hippocampal explants. Brain Res 378:398-404.

Frotscher M, Gähwiler BH (1988) Synaptic organization of intracellularly stained CA3 pyramidal neurons in slice cultures of rat hippocampus. Neuroscience 24:541-551.

Giaume C, McCarthy KD (1996) Control of gap-junctional communication in astrocytic networks. Trends Neurosci 19:319-325.

Giaume C, Marin P, Cordier J, Glowinski J, Premont J (1991) Adrenergic regulation of intercellular communications between cultured striatal astrocytes from the mouse. Proc Natl Acad Sci USA 88:5577-5581.

Haglund MM, Schwartzkroin PA (1984) Seizure-like spreading depression in immature rabbit hippocampus in vitro. Dev Brain Res 14:51-59.

Hamlyn LH (1962) The fine structure of the mossy fiber endings in the hippocampus of the rabbit. J Anat 96:112-120.

Heginbotham LR, Dunwiddie TV (1991) Long-term increases in evoked population spike in the CA1 region of rat hippocampus induced by $\beta$-adrenergic receptor activation. J Neurosci 11:2519-2527.

Herreras O, Largo C, Ibarez JM, Somjen GG, del Rio RM (1994) Role of neuronal synchronizing mechanisms in the propagation of spreading depression in the in vivo hippocampus. J Neurosci 14:7087-7098.

Kawahara N, Ruetzler CA, Klatzo I (1995) Protective effect of spreading depression against neuronal damage following cardiac arrest cerebral ischemia. Neurol Res 17:9-16.

Kobayashi S, Harris VA, Welsh A (1995) Spreading depression induces tolerance of cortical neurons to ischemia in rat brain. J Cereb Blood Flow Metab 15:721-727.

Koroleva VI, Bureś J (1979) Circulation of cortical spreading depression around electrically stimulated areas and epileptic foci of the neocortex of rats. Brain Res 173:209-215.

Koroleva VI, Bureś J (1980) Blockade of cortical spreading depression in electrically and chemically stimulated areas of cerebral cortex in rats. Electroencephalogr Clin Neurophysiol 48:1-15.

Kraig RP, Kunkler PE (1997) Hippocampal spreading depression may trigger migraine pain. Ann Neurol 42:A445.

Kraig RP, Dong L, Thisted R, Jaeger CB (1991) Spreading depression increases immunohistochemical staining of glial fibrillary acidic protein. J Neurosci 11:2187-2198.

Kunkler PE, Kraig RP (1997a) Reactive astrocytosis from excitotoxic injury in hippocampal organ culture parallels that seen in vivo. J Cereb Blood Flow Metab 17:26-43.

Kunkler PE, Kraig RP (1997b) Propagating calcium waves precede spreading depression. Ann Neurol 42:A435.

Largo C, Tombaugh GC, Aitken PG, Herreras O, Somjen GG (1997) 
Heptanol but not fluoroacetate prevents the propagation of spreading depression in rat hippocampal slices. J Neurophysiol 77:9-16.

Leão AAP (1944) Spreading depression of activity in the cerebral cortex. J Neurophysiol 7:359-390.

Liu S, Taffet S, Stoner L, Delmar M, Vallano ML, Jalife J (1993) A structural basis for the unequal sensitivity of the major cardiac and liver gap junctions to intracellular acidification: the carboxyl tail length. Biophys J 64:1422-1433.

Lorente de Nó R (1934) Studies on the structure of the cerebral cortex. II. Continuation of the study on the ammonic system. J Psychol Neurol (Leipz) 46:113-117.

Malenka RC (1994) Synaptic plasticity in the hippocampus: LTP and LTD. Cell 78:535-538.

Martin MR (1983) Naloxone and long-term potentiation of hippocampal CA3 field potentials in vitro. Neuropeptides 4:45-50.

Martins-Ferreira H, Ribeiro LJ (1995) Biphasic effects of gap junctional uncoupling agents on the propagation of retinal spreading depression. Braz J Med Biol Res 28:991-994.

Matsushima K, Hogan MJ, Hakim AM (1996) Cortical spreading depression protects against subsequent focal cerebral ischemia in rats. J Cereb Blood Flow Metab 16:221-226.

Moudy AM, Schwartzkroin PA (1992) Pyramidal neurons in immature rat hippocampus are sensitive to $\beta$-adrenergic agents. Brain Res 67:57-66.

Mueller AL, Hoffer BJ, Dunwiddie TV (1981) Noradrenergic responses in rat hippocampus: evidence for mediation by $\alpha$ and $\beta$ receptors in the in vitro slice. Brain Res 214:113-126.

Muller GM, Buchs PA, Stoppini L (1993) Time course of synaptic development in hippocampal organotypic cultures. Dev Brain Res 71:93-100.

Nedergaard M (1994) Direct signaling from astrocytes to neurons in cultures of mammalian brain cells. Science 263:1768-1771.

Nedergaard M, Cooper AJL, Goldman S (1995) Gap junctions are required for the propagation of spreading depression. J Neurobiol 28:433-444.

Newman EA (1995) Glial cell regulation of extracellular potassium. In: Neuroglia (Kettenmann H, Ransom BR, eds), pp 717-731. New York: Oxford.

Newman EA, Zahs KR (1997) Calcium waves in retinal glial cells. Science 275:844-848.

Nicholson C (1995) Extracellular space as the pathway for neuron-glial cell interaction. In: Neuroglia (Kettenmann H, Ransom BR, eds), pp 387-397. New York: Oxford.

Nicholson C, Kraig RP (1981) The behavior of extracellular ions during spreading depression. In: The application of ion-selective microelectrodes (Zeuthen T, ed), pp 217-238. Amsterdam: Elsevier/ North-Holland.

Parpura V, Basarsky TA, Liu F, Jeftinija K, Jeftinija S, Haydon PG
(1994) Glutamate-mediated astrocyte-neuron signaling. Nature 369:744-747.

Perez-Velazquez JL, Valiante TA, Carlen PL (1994) Modulation of gap junctional mechanisms during calcium-free induced field burst activity: a possible role for electrotonic coupling in epileptogenesis. J Neurosci 14:4308-4317.

Post RM, Silberstein SD (1994) Shared mechanisms in affective illness, epilepsy, and migraine. Neurology 44[Suppl 7]:S37-S47.

Psarropoulou C, Avoli M (1993) 4-Aminopyridine-induced spreading depression episodes in immature hippocampus: developmental and pharmacological characteristics. Neuroscience 55:57-68.

Ramon y Cajál S (1995) Fourth order olfactory areas: Ammon's horn and the dentate gyrus. In: Histology of the nervous system, Vol II, Chap XXXI (Swanson N, Swanson LW, translators), pp 603-657. New York: Oxford UP.

Roos A, Boron WF (1981) Intracellular pH. Physiol Rev 61:296-434.

Snow RW, Taylor CP, Dudek FE (1983) Electrophysiological and optical changes in slices of rat hippocampus during spreading depression. J Neurophysiol 50:561-572.

Somjen GG, Aitken PG, Czéh GL, Herreras O, Jing J, Young JN (1992) The mechanisms of spreading depression: a review of recent findings, and a hypothesis. Can J Physiol Pharmacol [Suppl] 70:S248-S254.

Spray DC, Bennett MVL (1985) Physiology and pharmacology of gap junctions. Annu Rev Physiol 47:281-303.

Spray DC, Harris AL, Bennett MVL (1981) Gap junctional conductance is a simple and sensitive function of intracellular $\mathrm{pH}$. Science 211:712-715.

Takano K, Latour LL, Formato JE, Carano RA, Helmer KG, Hasegawa Y, Sotak CH, Fisher M (1996) The role of spreading depression in focal ischemia evaluated by diffusion mapping. Ann Neurol 39:308-318.

Taylor CP, Dudek FE (1984) Excitation of hippocampal cells by an electrical field effect. J Neurophysiol 52:126-142.

van den Pol AN, Finkbeiner SM, Cornell-Bell AH (1992) Calcium excitability and oscillations in suprachiasmatic nucleus neurons and glia in vitro. J Neurosci 12:2648-2664.

Wang Z, Tymianski M, Jones OT, Nedergaard M (1997) Impact of cytoplasmic calcium buffering on the spatial and temporal characteristics of intercellular calcium signals in astrocytes. J Neurosci 17:7359-7371.

Whitfield JF (1990) Calcium, cell cycles, and cancer. Boca Raton, FL: CRC.

Yamamoto C, Kawai N (1967) Seizure discharges evoked in vitro in thin section from guinea pig hippocampus. Science 155:341-342.

Zimmer J, Gähwiler BH (1984) Cellular and connective organization of slice cultures of the rat hippocampus and fascia dentata. J Comp Neurol 228:432-446. 